\title{
Study on Lip Prints-To Estimate the Reliability as a Personal Identification Method
}

\author{
Sivan P Priya ${ }^{1}$, Al Anoud Salem² ${ }^{2}$ Ahoud Almadhani ${ }^{3}$, Shibu Thomas ${ }^{4}$, Sajith Bhaskar ${ }^{5}$, Captain Kholoud H Alkhaldi ${ }^{6}$, \\ Hassan AM Al Samahi ${ }^{7}$, Alradaideh Ahmed $^{8}$
}

\begin{abstract}
Aim: Lip prints are unique for any individual. The potential of lip prints as one of the biometric records to determine the identity has been well-recognized. However, studies focused on their reliability by comparing the developed latent lip prints were scarce. This study focused on the reliability of the lip prints for the personal identification by comparing the registered lip prints with the developed latent lip prints made on the porcelain cups.

Materials and methods: Samples of 102 subjects (52 males and 50 females) within the age group of 18-30 years were included. Latent and superimposed lip impressions were made on a standard porcelain cup. The latent prints were developed with the fingerprint powder. Then, the lip prints with lip rouge were registered on a transparent adhesive tape. Both the developed latent lip prints and the registered lip prints were photographed with a standard ruler using the digital camera and were compared. The lip prints were classified with the scheme proposed by Tsuchihashi. The statistical analysis was done using the Pearson Chi-square test (IBM SPSS version 20) with a $p$ value of 0.05.

Results: The lip prints were unique to any individual irrespective of the gender variation. Their interpretation of comparing the digital pictures confirmed the presence of unique patterns and the possibility of the feature extraction similar to the fingerprints. Type III was the most frequent pattern observed in the study group.

Conclusion: We conclude that the lip prints are highly reliable as a biometric record due to their uniqueness. The lip prints have demonstrated enough evidence that is intentionally registered and the developed latent prints were compared, which can be applied as one of the easiest and simplest methods for comparison. Yet, the authenticity of the lip print is in the preliminary level and need more systematic studies to be accepted for the legal disputes.

Clinical significance: The study result can strengthen the reliability of the lip prints as an identification tool and discusses the future possibilities of lip print application.

Keywords: Biometrics, Fingerprints, Forensic odontology, Lip prints.

World Journal of Dentistry (2019): 10.5005/jp-journals-10015-1629
\end{abstract}

\section{INTRODUCTION}

The recognized personal identification methods are DNA matching, fingerprinting, and dental methods (www.interpol.int). The uniqueness of the lip prints has been proved, ${ }^{1}$ yet the reliability is still under debate due to the lack of authentic and acceptable research works reported. We need lip print studies mimicking the crime scene analysis. Biometric identification or simply as biometrics is a process of referring identification of a person based on his/her behavioral or physiological features, which satisfy the uniqueness, universality, permanence, collectability, acceptance, and circumvention. ${ }^{2}$ The flow of the ridges, the features present along the ridges, and their sequences are the information collected from the fingerprints. The comparable technology can very well be applied to the lip prints as well. Currently, biometrics has extended from the fingerprints to iris, palm prints, and facial recognition, and constantly adapts newer innovations. The acquired information of biometrics is operated by different modes, namely "verification or positive recognition", which compares the acquired record only with the claimed identity and the "identification or negative recognition", which compares the acquired record with all other records in the database to confirm the identity and to avoid one person with many identities. ${ }^{2}$ The practical application of lip prints for 'verification' lacks convincing accurate methods, unlike the currently recognized identification methods. While for the 'identification' purpose, the advantages of the uniqueness of the lip prints need to be raised.
${ }^{1}$ Department of Basic Medical Sciences; Department of Surgical Sciences, Ajman University, Fujairah Campus, Fujairah, United Arab Emirates

2,3 Department of Dentistry, Ajman University, Fujairah Campus, Fujairah, United Arab Emirates

${ }^{4}$ Department of Restorative Dentistry, College of Dentistry, Ajman University, Fujairah Campus, Fujairah, United Arab Emirates

${ }^{5}$ Department of Pedodontics and Preventive Dentistry, Specialized Kalba Dental Centre, Ministry of Health and Prevention, United Arab Emirates

${ }^{6,7}$ Department of Crime Scene; Department of Criminal Evidence, General Directorate of Police Operations, General Command of Police Al-Fujairah, Fujairah, United Arab Emirates

${ }^{8}$ Department of Dentistry, Unit of General Studies, Ajman University, Fujairah Campus, Fujairah, United Arab Emirates

Corresponding Author: Sivan P Priya, Department of Basic Medical Sciences; Department of Surgical Sciences, Ajman University, Fujairah Campus, Fujairah, United Arab Emirates, Phone: +971 505365198, e-mail: priyaganu@yahoo.com

How to cite this article: Priya SP, Salem A, et al. Study on Lip PrintsTo Estimate the Reliability as a Personal Identification Method. World J Dent 2019;10(3):186-191.

Source of support: Nil

Conflict of interest: None

(c) The Author(s). 2019 Open Access This article is distributed under the terms of the Creative Commons Attribution 4.0 International License (https://creativecommons. org/licenses/by-nc/4.0/), which permits unrestricted use, distribution, and non-commercial reproduction in any medium, provided you give appropriate credit to the original author(s) and the source, provide a link to the Creative Commons license, and indicate if changes were made. The Creative Commons Public Domain Dedication waiver (http://creativecommons.org/publicdomain/zero/1.0/) applies to the data made available in this article, unless otherwise stated. 
Sir Francis Galton first identified the fingerprint patterns, and the characteristics of the fingerprints are named as "Galton points" or "minutiae" after him. These minutiae were used to develop automated fingerprint technology (AFPT) after computer technology has taken over the manual interpretations. During 1994, the integrated automated fingerprint identification system (IAFIS) has been evolved to communicate and exchange information between synchronized systems. The growth within few decades was tremendous due to continuous and robust research on fingerprints, which is missing with the lip print methods due to the insufficient and reliable research reports. The sensors used to sense the minutiae are different in varieties namely optical, capacitive, ultrasound, and thermal, among them optical sensors are most commonly used (capacitance-determines each pixel value with the area or air, ultrasound-light reflectance changes, and thermalthe difference in temperature). ${ }^{3}$ Unfortunately, the ability of these sensors to validate the lip prints has not been reported.

The considered attributes in forensic odontology are dental age estimation, odontometric analysis, bite mark analysis, cheiloscopy, and rugoscopy. ${ }^{4}$ Cheiloscopy examines the grooves, furrows, wrinkles, and valleys of the vermilion zone of the lip. The lip prints are formed as early as the sixth week of intrauterine life and remain the same for life. ${ }^{5}$ The lip prints have proved its uniqueness with more individual characteristic patterns within a small area. ${ }^{6-9}$ The genuine research on lip prints in the past few decades made FBI to conduct a workshop on cheiloscopy (USA, 1995). ${ }^{10}$ Lip prints are being studied in the aspects such as their ability to recover back to the original pattern after injury by trauma or infections, the similarities between siblings and families, and about the gender variations. ${ }^{11,12}$ Even though the reported research was diverse and within the small groups, they have proved that the lip prints are fundamentally similar to the fingerprints. The current study was designed with the primary objective of comparing the intentionally registered lip prints with the developed latent lip prints. Also, we have verified the uniqueness, gender variations, and the predominant lip print pattern.

\section{Materials and Methods}

\section{Selection of Participants and Method of Collection}

The sample was composed of 102 subjects within the age group of 18 to 30 years male $(n=52)$ and female $(n=50)$ of Ajman UniversityFujairah branch students. The Ajman University ethical committee had approved the study (ref. BS-2014/15-01). The participants were explained about the study and the informed consent was signed. Individuals having lesions on the lips and/or with known hypersensitivity to lipsticks were excluded. Latent and superimposed lip impressions were made on a standard porcelain cup with ten sips within the time of two minutes (without lip rouge) and developed with the fingerprint powder (Fig. 1A). Lip rouge was applied with a disposable applicator, and a strip of transparent cellophane tape with the sticky side touching the lip was patted to obtain the prints and recorded on a white sheet without disclosing the identity (Fig. 1B). The sorting scheme proposed by Tsuchihashi ${ }^{13}$ was used to classify the lip patterns and the data were statistically analyzed. The classification was described as type l: clear grooves running across the lip vertically; type I': the grooves like type I but do not run the entire height of the lip; type Il: the grooves that divide become fork; type III: the intersecting grooves; type IV: the reticular grooves; and type V: the grooves cannot be differentiated into any type (Fig. 2).

The lip prints intentionally registered on the papers and the developed latent lip prints on the cups with fingerprint powder were

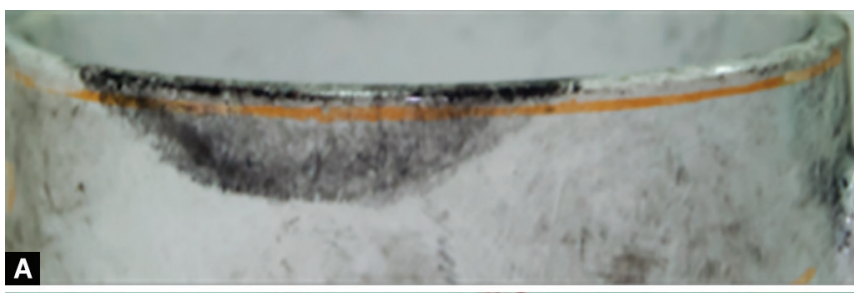

A

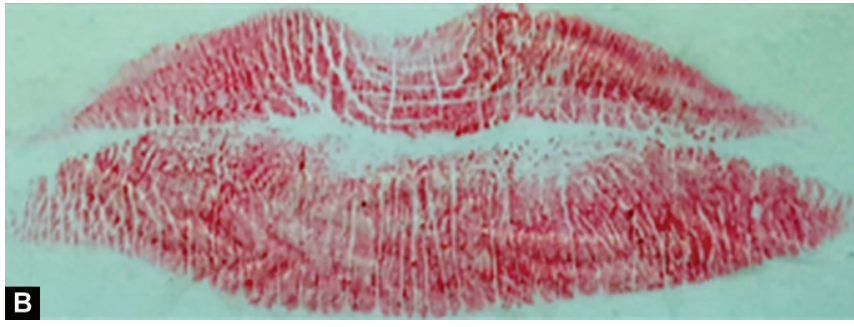

Figs $1 \mathrm{~A}$ and B: (A) Latent and superimposed lip impressions made on a standard porcelain cup with ten sips within the time of two minutes (without lip rouge) and developed with the fingerprint powder; (B) Lip rouge was applied with a disposable applicator and a strip of transparent cellophane tape with the sticky side touching the lip was patted to obtain the prints and recorded on a white sheet without disclosing the identity

photographed with the digital camera (Nikon D5100DSLR). Each lip print picture was divided into equal eight segments for the detailed evaluation of the features (Fig. 3). The segments close to the midline were numbered as 1 and away from it were numbered as 2 . It was noticed that each segment of the lips displayed different predominant types and no typed feature was present alone in any segment. The predominant pattern in each segment was recorded. The results were analyzed according to the distribution of the different patterns and the predominant pattern among the different segments and between the genders (Fig. 4). Statistical analysis was done using the Pearson Chi-square test (IBM SPSS version 20) with a $p$ value of 0.05 .

The cup impressions displayed the part of right lower 1 (RL1) and left lower 1 (LL1) quadrants. Digital pictures of the cup impressions were marked on the predominant patterns or features with red colored dots and the intentionally registered lip prints were marked with dark green colored dots in the same quadrants for comparison. The grooves on the lip leave the space without any impression on the paper and cup after development with the fingerprint powder. The intersecting points of type II, III, and IV were marked as the reference points similar to the minutiae of the fingerprints. Unlike the intersecting lines in all other types, type I was challenging to locate with the reference point.

The digital pictures of the intentionally registered lip prints and the developed latent cup prints were compared with the same and different individuals. Despite the standard techniques and clear instructions and no beverage kept during the sipping of the cup for impression, only $25 \%$ of the cup impressions were acceptable to extract the features. This can be due to the superimposed features, how the subjects sip, and hold the cup.

There were 10 samples selected from each gender for comparison. Each sample was compared with 19 samples (which are the selected 10 samples from each gender). Since it was a visual interpretation and the human error was possible, two of the fingerprint experts from the Fujairah forensic department were requested to analyze the different features of the lip prints.

The participants were mainly from the Arab origin (Bahrain (3), Egypt (3), Iran (3), Iraq (14), Jordon (16), Kuwait (12), Oman (3), 

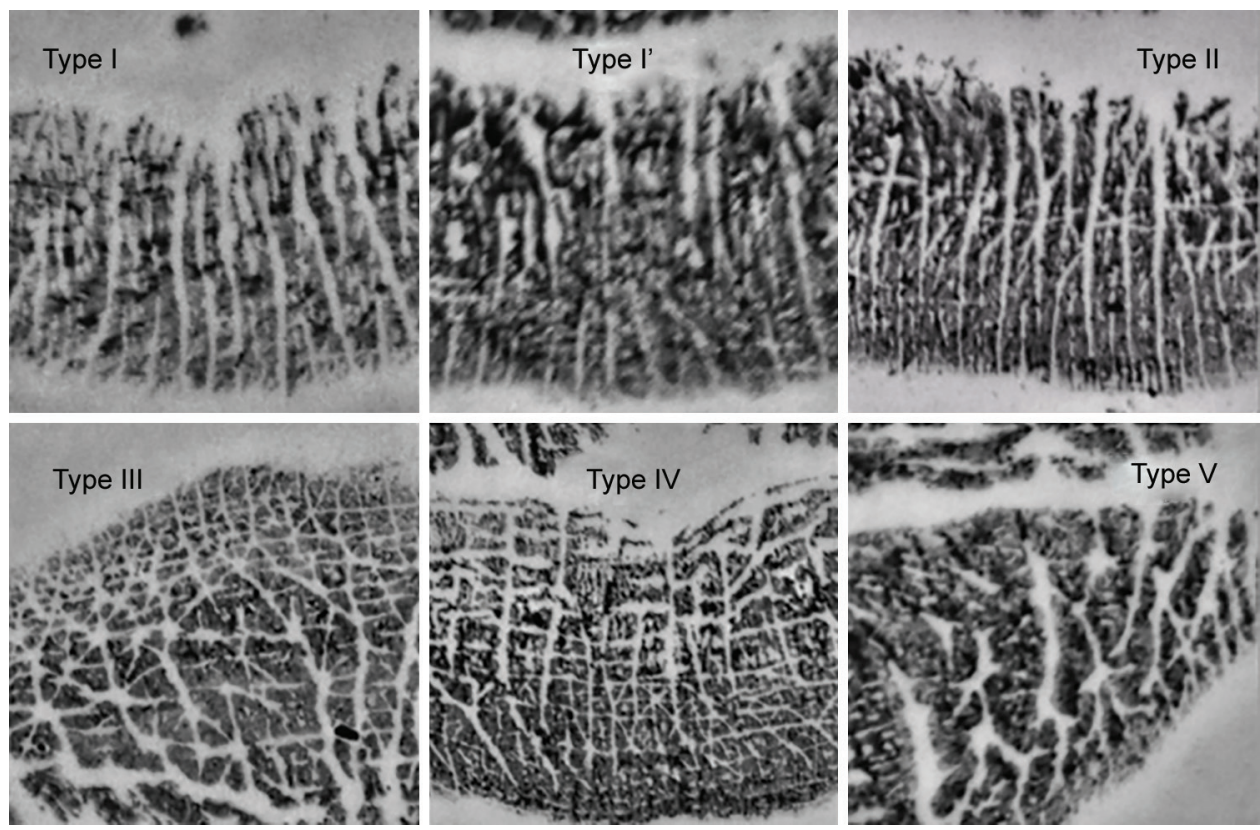

Fig. 2: Types of lip prints as proposed by Tsuchihashi 1974. The classification was described as type l: clear grooves running across the lip vertically; type I': the grooves like type I but do not run the entire height of the lip; type II: the grooves that divide become fork; type III: the intersecting grooves; type IV: the reticular grooves; and type V: the grooves cannot be differentiated into any type

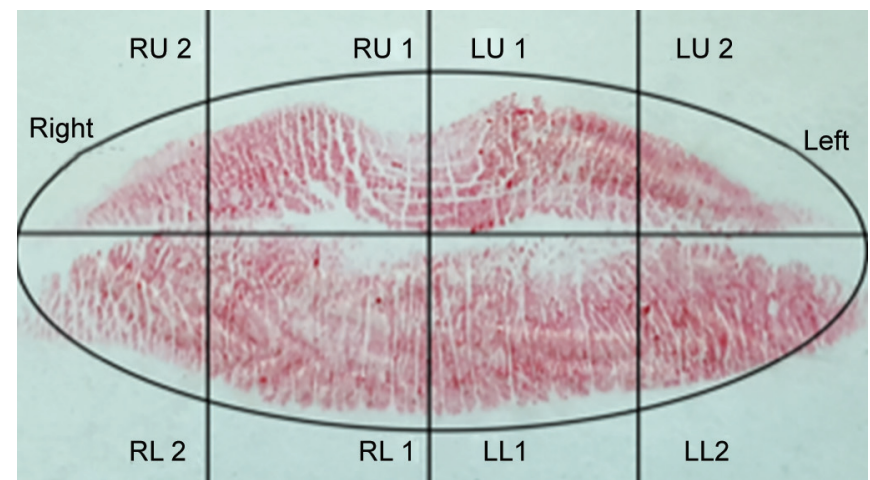

Fig. 3: Each lip print picture was divided into equal eight segments for the detailed evaluation of the features. The segments close to the midline were numbered as 1 and away from it were numbered as 2 . $\mathrm{RU}$, right upper; LU, left upper; LL, left lower; RL, right lower

Palestine (5), Saudi (1), Sudan (4), Syria (20), and UAE (17), totally 94 Arab participants), few from Asia (India (3) and Pakistan (1), totally 4 participants), and one participant each from America, Canada, New Zealand, and Tanzania. The principal aim of this study was to compare the intentionally registered and the developed latent lip prints. Since the study had participants from eighteen countries, it was added as another parameter. However, the number of participants from each country was ranged from 1 to 20 , which was not ideal for the statistically significant evaluation and the results were not added. However, it was found that the used classification can be applied and the recorded lip prints did not show any unique presentation particular to the participants of any country of origin.

\section{Results}

The developed cup impressions with impressive features were only $25 \%$. The selected digital pictures of the developed latent

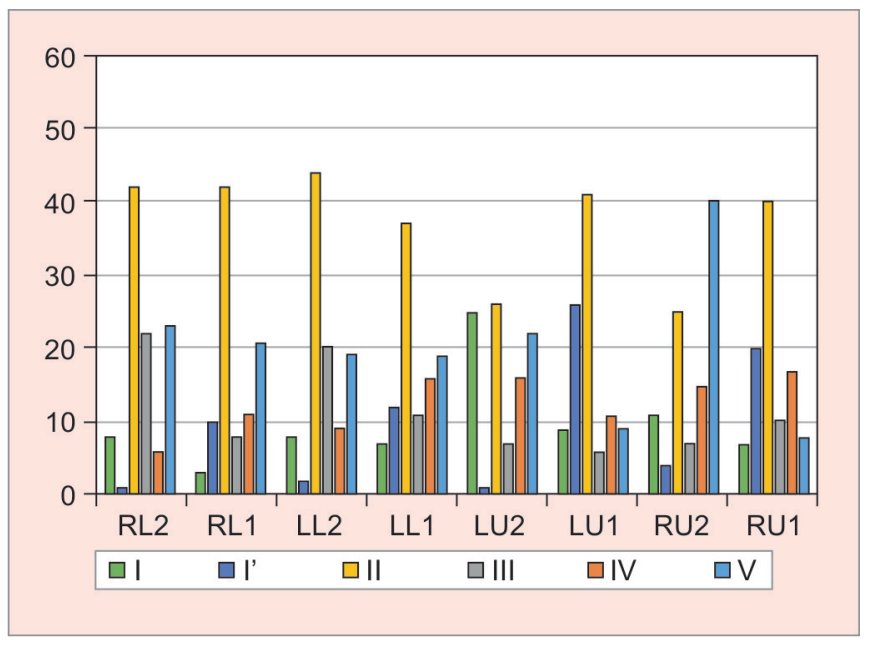

Fig. 4: Frequency of the lip print types recorded in each segment including both the genders. RU, right upper; LU, left upper; LL, left lower; $\mathrm{RL}$, right lower; segment close to midline was numbered as 1 and away from it was numbered as 2 . Type III was recorded as the most frequent pattern among all the participants

impressions on the cup and the registered lip prints were analyzed and it was found that sufficient features were available to interpret with the recorded impressions. Their interpretation of comparing the digital pictures confirmed the presence of unique patterns and the possibility of the feature extraction similar to the fingerprints. The current study report revealed that the most frequent pattern was type III and the least common was type V. It was detected that each segment of the lips had displayed different predominant types. Also, no typed feature was present alone in any segment and so the predominant type was recorded. All the segments displayed type III as a predominant pattern except in the right upper 2 (RU2) segment where type I was prominent. Type I was the second frequent pattern 
followed by type I', type II, and type IV in the descending order of frequency. Type $V$ was the least common except in the left upper 2 (LU2) segment. The gender variations were not significant with the current report except in right upper 1 (RU 1) ( $p$ value 0.001) and left lower 1 (LL 1) ( $p$ value 0.04 ) segments. This study was preliminary research with limited samples, but an initiating step for future modifications will lead to a more acceptable and advanced method in the lip print analysis.

\section{Discussion}

The escalating crime rates, accumulating unresolved cases, and cleverer suspects mandate new identification possibilities. The lip prints in the crime scene were typically collected from the coffee cups, cigarette butts, window surfaces, and body surfaces in case of abuse, around the bite marks on foodstuffs or body surfaces. ${ }^{10}$ Unlike the fingerprint methods, the lip print methods are not well evaluated by organized studies. The porcelain cup was selected in the current study to extract the original possible latent prints from evaluating the available features. A study by Dwivedi et al. compared the developed latent prints of the entire lip on a glass slab and revealed that about $29 \%$ exhibited good prints in all quadrants after development and the matching possibility varied from 50 to $100 \% ;{ }^{14}$ this was congruent with our study of $25 \%$ comparable quality prints. These studies on lip prints revealed that the extraction of the salient features from the source is the primary challenge. Our study confronted the same challenges, yet there were features available for the evaluation.

Similar to fingerprints, lip prints are unique to an individual; this was established in our study. Studies conducted in families have established that the lip prints are not identical even in identical and non-identical twins. ${ }^{7,15}$ The distinct predominant pattern in each segment of the same individual and the statistically insignificant gender variations shown in our study strengthen the uniqueness of the lip prints.

Lip print studies were always on a pursuit for the most frequent patterns. Our study complies with the result reported by Suzuki and Tsuchihashi in 1974 and by many other researchers ${ }^{6,13,16,17}$ that type III lip print as the most frequent one. However, some studies have reported that type I was a predominant pattern ${ }^{18-21}$ and few reported it as rare. ${ }^{22}$ Type $V$ was found to be less frequent by past studies. ${ }^{7}$ Unlike the fingerprints, the lip prints are influenced by stretch, contraction and the muscle tone of the lip, and the orofacial muscles. The muscle tone decreases with aging, which was considered during evaluation in few studies. ${ }^{16}$

The participants of the current study were from 18 countries. Since the samples from each country were small, it was statistically insignificant. However, the study proved that the Tsuchihashi's classification could be applied for the people of different nationalities and it was established that the lip prints are unique irrespective of different ethnic origins. Researchers have reported a significant difference between the male and female lip print patterns and suggested that the larger size of the male lip should be investigated ${ }^{1,20,22-24}$ and a proportion denies it. ${ }^{18,25,26}$ Even though these studies can fortify the literature, the type of assessments has a narrow range of application because the lip size variation between genders may display a wide variation with the female of one ethnic group when compared to that of the male of another ethnic group.

Developing the latent prints and capturing them as digital images are the crucial aspects of the forensic evidence investigation since any mishandling can misinform the legal proceedings. ${ }^{14,27}$
Our study demonstrated that the techniques used for fingerprint could also be used for lip prints because both of them are comparable and the fingerprint techniques with different materials and surfaces are already standardized. Different uses of the lip prints have been analyzed in many types of research such as the extraction of DNA from lip prints ${ }^{29}$ and their use as a genetic or hereditary pattern to compare between parents and siblings. ${ }^{12,17}$ A study about the lip prints on the atypical surfaces has been reported as successful. ${ }^{30}$ However, many studies tried to relate the blood group and the lip prints and found negative results. ${ }^{31-35} \mathrm{~A}$ study correlated the association of the whorl pattern of the lip prints with the cleft lip and cleft syndromes. ${ }^{36}$ The lip pattern with a vertical type is significantly correlated with skeletal class II malocclusion. ${ }^{37}$ An exciting study stated the presence of differences in lip prints among the different populations of Kerala and Manipuri states of India. ${ }^{38}$ Population-based studies need more collaborative work. A large volume of research works had concluded that the lip prints could be utilized as an additional tool for forensic investigation. 8,26,39,40

The court of law expects evidence with nil flaws, which is the utmost important factor to be considered in future studies related to lip prints and not just the pattern oriented reports. Besides, the restriction of the lip prints validity concerning age-related changes, ${ }^{41}$ environmental factors, and disease processes especially mucocutaneous lesions ${ }^{40}$ need to be evaluated.

Medical evidence is susceptible to errors during application including the primary methods of identification like fingerprints and DNA evidence. ${ }^{42}$ The DNA extraction for the lip prints was also an added possibility as primary evidence. ${ }^{43,44}$ Since the certainty in reproducibility of DNA evidence is higher at any time and at any place from the same individual, it was named as 'hard evidence' in contrast to the 'soft evidence' like fingerprints, lip prints, voice recording, and handwriting. This soft evidence is more susceptible to the vulnerable questions about the scientific basis of evidence, the probability of the assessment accuracy, and the reproducibility from the same individual with the same feature. ${ }^{2}$ The continually changing nature of the science should not alter the judgment, which will lead to impediment in accepting the scientific evidence. The soft evidence such as lip prints can be strengthened by adopting the standards in quality by modifying the techniques applied; by improving the quantity of the number of reference points added for comparisons; self-regulated forensic associations to provide standards and accreditation; research studies to reduce the possibilities of the human error; double-blind examination, and by encouraging and approving the new techniques for better validity and reliability.

Single biometric characteristic (unimodal) such as lip prints has limitations almost certainly, which can be rectified by more dynamic multimodal biometrics, which uses physical and behavioral biometric signals to achieve better reliability. ${ }^{45,46}$ Research based on computer-aided techniques has claimed that these techniques can detect and compare the local features from different sizes of images or rotated images of the same lip and even from the deformed lip prints. ${ }^{45}$ If this is accepted, it will be a great added benefit in lip print identification because unlike the fingerprints, the lip prints were deformed continuously by the movement of the lips; ${ }^{45}$ also the artificial intelligence with the face recognition can be strengthened with the lip prints.

The uniqueness of the lip prints has not been investigated with impeccable practical application. The increase in demand for multimodal biometrics in criminal, civil, and banking fields 
necessitates more added biometric features to support. The smart face identification technologies can be modified to capture and comprise the lip shape, size, and prints. These applications if developed and succeeded the standardization, a selfie or a facial image with the lip prints might replace the fingerprint verifications. As per our knowledge, this is the first research work done in this aspect and we do recommend more modifications mandatory for the standardization of the techniques in future, such as increasing the sample size and applying the automated feature extraction techniques similar to fingerprints to prevent the human error and to improve the output to validate the evidence.

\section{Conclusion}

The various procedures such as registration, recording, developing the lip prints from the latent prints, and identification, interpretation, and analysis of the lip prints need to be standardized to gain universal acceptance as a secondary identification method. $\mathrm{FBl}$ is proceeding with a project of next generation identification (NGI), intending to extend the capabilities of using IAFIS by incorporating palm prints, iris, and the facial features of identifications (www.fbi.gov). Since the uniqueness of the lip prints was well established, researchers need to standardize the techniques of feature extraction and evaluation to adopt in biometrics. The fingerprint experts, engineering experts of biometric techniques, computer technologists, and the forensic odontologists need to work together by sharing their knowledge to bring more acceptable techniques to aid the law. Despite its uniqueness, the current level of research evidence on the authenticity of the lip prints is not enough to conclude it as a statistically acceptable identification method due to the deficiency in quantitative and qualitative research.

\section{Acknowledgments}

We thank the Ajman University_Fujairah Branch for the generous support. The staff and students of AU-Fujairah participated in this study were highly appreciated. Our thanks to Fujairah Forensic Department for the training and the extended help to complete this study by supporting scientifically and technically for the development of the lip prints, providing expert view, and the extended guidance during the manual interpretations.

\section{References}

1. Kautilya DV, Bodkha P, et al. Efficacy of cheiloscopy in determination of sex among South Indians. J Clin Diagn Res 2013;7(10):2193-2196. DOI: $10.7860 / J C D R / 2013 / 5371.3468$.

2. Jain AK. Biometric Recognition: Overview and Recent Advances. In: Rueda L, Mery D, et al. ed. Progress in Pattern Recognition, Image Analysis and Applications. Lecture Notes in Computer Science vol. 4756, Berlin: Springer, Heidelberg CIARP; 2007. DOI: 10.1007/9783-540-76725-1_2.

3. Woodward JD, Orlans NM, et al. Biometrics. New York: McGraw-Hill/ Osborne; 2003. p. 432, vol. xxvii.

4. Nagalaxmi V, Ugrappa S, et al. Cheiloscopy, Palatoscopy and Odontometrics in Sex Prediction and Dis-crimination - a Comparative Study. Open Dent J 2014;8:269-279.

5. Vats Y, Dhall JK, et al. Gender variation in morphological patterns of lip prints among some north Indian populations. J Forensic Dent Sci 2012;4(1):19-23. DOI: 10.4103/0975-1475.99155.

6. Sivapathasundharam B, Prakash PA, et al. Lip prints (cheiloscopy). Indian J Dent Res 2001;12(4):234-237.

7. Kumar GS, Vezhavendhan N, et al. A study of lip prints among Puducherry population. J Forensic Dent Sci 2012;4(2):84-87. DOI: 10.4103/0975-1475.109894.
8. Venkatesh R, David MP. Cheiloscopy: An aid for personal identification J Forensic Dent Sci 2011;3(2):67-70. DOI: 10.4103/0975-1475.92147.

9. Prasad P. A comparison of lip prints between Aryans-Dravidians and Mongols. Indian J Dent Res 2011;22(5):664-668. DOI: 10.4103/09709290.93453.

10. Ball J. The current status of lip prints and their use for identification. J Forensic Odontostomatol 2002;20(2):43-46.

11. Hirth L, Gottsche H, et al. [Lip prints-variability and genetics (author's transl)]. Humangenetik 1975;30(1):47-62. DOI: 10.1007/BF00273631.

12. Gupta S, Gupta K, et al. A study of morphological patterns of lip prints in relation to gender of North Indian population. J Oral Biol Craniofac Res 2011;1(1):12-16. DOI: 10.1016/S2212-4268(11)60005-5.

13. Tsuchihashi Y. Studies on personal identification by means of lip prints. Forensic Sci 1974;3(3):233-248. DOI: 10.1016/0300-9432(74)90034-X.

14. Dwivedi N, Agarwal A, et al. Latent lip print development and its role in suspect identification. J Forensic Dent Sci 2013;5(1):22-27. DOI: 10.4103/0975-1475.114554.

15. El Domiaty MA, Al-gaidi SA, et al. Morphological patterns of lip prints in Saudi Arabia at Almadinah Almonawarah province. Forensic Sci Int 2010;200(1-3):179.

16. Augustine J, Barpande SR, et al. Cheiloscopy as an adjunct to forensic identification: a study of 600 individuals. J Forensic Odontostomatol 2008;26(2):44-52.

17. Devi A, Astekar M, et al. The study of inheritance analysis and evaluation of lip prints in individuals. J Forensic Dent Sci 2015;7(1): 49-53. DOI: 10.4103/0975-1475.150309.

18. Chiu CS, Clark RK. The facial soft tissue profile of the southern Chinese: prosthodontic considerations. J Prosthet Dent 1992;68(5):839-850. DOI: 10.1016/0022-3913(92)90214-U.

19. Bansal N, Sheikh S, et al. Correlation between lip prints and fingerprints in sex determination and pattern predominance in 5000 subjects. J Forensic Odontostomatol 2013;31(1):8-14.

20. Multani S, Thombre V, et al. Assessment of lip print patterns and its use for personal identification among the populations of Rajnandgaon, Chhattisgarh, India. J Int Soc Prev Community Dent 2014;4(3):170-174. DOI: $10.4103 / 2231-0762.142018$.

21. Peeran SW, Kumar PG, et al. A study of lip print patterns among adults of Sebha city, Libya. J Forensic Dent Sci 2015;7(1):67-70. DOI: 10.4103/0975-1475.150322.

22. Karki RK. Lip prints: an identification aid. Kathmandu Univ Med J (KUMJ) 2012;10(38):55-57.

23. Nagasupriya A, Dhanapal R, et al. Patterns - "A crime solver".J Forensic Dent Sci 2011;3(1):3-7. DOI: 10.4103/0975-1475.85282.

24. Sharma $V$, Ingle NA, et al. Identification of sex using lip prints: A clinical study. J Int Soc Prev Community Dent 2014;4(Suppl 3):S173-S177. DOI: 10.4103/2231-0762.149030.

25. Padmavathi BN, Makkad RS, et al. Gender determination using cheiloscopy. J Forensic Dent Sci 2013;5(2):123-128. DOI: 10.4103/09751475.119780

26. Ragab AR, El-Dakroory SA, et al. Characteristic patterns of lip prints in Egyptian population sample at Dakahlia Governorate. J Leg Med 2013;127(2):521-527. DOI: 10.1007/s00414-012-0784-5.

27. Wen $\mathrm{CY}, \mathrm{Yu}$ CC. Fingerprint pattern restoration by digital image processing techniques. J Forensic Sci 2003;48(5):973-984. DOI: 10.1520/JFS2002385.

28. Chowdhry A, Sircar K, et al. Image manipulation: fraudulence in digital dental records: study and review. J Forensic Dent Sci 2014;6(1):31-35. DOI: $10.4103 / 0975-1475.127767$.

29. Castello A, Alvarez M, et al. Just lip prints? No: there could be something else. FASEB J 2004;18(6):615-616. DOI: 10.1096/fj.03-0938lfe.

30. Fonseca GM, Bonfigli $E$, et al. Experimental model of developing and analysis of lip prints in atypical surface: A metallic straw (bombilla). J Forensic Dent Sci 2014;6(2):126-131. DOI: 10.4103/09751475.132543.

31. Karim B, Gupta D. Cheiloscopy and blood groups: Aid in forensic identification. Saudi J Dent Res 2014;26(4):176-180. DOI: 10.1016/ j.sdentj.2014.05.005. 
32. Srilekha N, Anuradha A, et al. Correlation among lip print pattern, fingerprint pattern and $A B O$ blood group. J Clin Diagn Res 2014;8(3):49-51.

33. Verma P, Sachdeva SK, et al. Correlation of Lip Prints with Gender, ABO Blood Groups and Intercommissural Distance. N Am J Med Sci 2013;5(7):427-431. DOI: 10.4103/1947-2714.115777.

34. Ashwinirani SR, Suragimath G, et al. Comparison of Lip Print Patterns in Two Indian Subpopulations and Its Correlation in ABO Blood Groups.J Clin Diagn Res 2014;8(10):ZC40-ZC43. DOI: 10.7860/JCDR/2014/9864.5001.

35. Telagi N, Mujib A, et al. Cheiloscopy and its patterns in comparison with ABO blood groups. J Forensic Dent Sci 2011;3(2):77-80. DOI: 10.4103/0975-1475.92150.

36. Neiswanger K, Walker K, et al. Whorl patterns on the lower lip are associated with nonsyndromic cleft lip with or without cleft palate. Am J Med Genet, Part A 2009;149(12):2673-2679. DOI: 10.1002/ajmg.a.33089.

37. Raghav P, Kumar N, et al. Lip prints: The barcode of skeletal malocclusion. J Forensic Dent Sci 2013;5(2):110-117. DOI: 10.4103/0975-1475.119777.

38. Koneru A, Surekha R, et al. Comparison of lip prints in two different populations of India: Reflections based on a preliminary examination. J Forensic Dent Sci 2013;5(1):11-15. DOI: 10.4103/0975-1475.114543.

39. Prabhu RV, Dinkar A, et al. A study of lip print pattern in Goan dental students - A digital approach. J Forensic Leg Med 2012;19(7):390-395. DOI: 10.1016/j.jflm.2012.04.012.
40. Sandhu SV, Bansal H, et al. Study of lip print pattern in a Punjabi population. J Forensic Dent Sci 2012;4(1):24-28. DOI: 10.4103/09751475.99157.

41. Randhawa K, Narang RS, et al. Study of the effect of age changes on lip print pattern and its reliability in sex determination. J Forensic Odontostomatol 2011;29(2):45-51.

42. Ulery BT, Hicklin RA, et al. Accuracy and reliability of forensic latent fingerprint decisions. Proc Natl Acad Sci U S A 2011;108(19):7733-7738. DOI: 10.1073/pnas.1018707108.

43. Sharma P, Sharma N, et al. Can lip prints provide biologic evidence? J Forensic Dent Sci 2016;8(3):175. DOI: 10.4103/0975-1475. 195101.

44. Dineshshankar J, Ganapathi N, et al. Lip prints: Role in forensic odontology. J Pharm BioAllied Sci 2013;5(suppl 1):S95-S97. DOI: 10.4103/0975-7406.113305.

45. Choi H, Park H. A Multimodal User Authentication System Using Faces and Gestures. BioMed Res Int 2015;2015:343475. DOI: 10.1155/2015/343475.

46. Rinaldi A. Biometrics' new identity-measuring more physical and biological traits: Research into the characteristics that are unique to an individual is addressing the need to correctly identify people in a variety of medical, social and security contexts. EMBO Rep 2016;17(1):22-26. DOI: 10.15252/embr.201541677. 